\title{
The Arizona Intimate Partner Homicide (AzIPH) Study: a Step toward Updating and Expanding Risk Factors for Intimate Partner Homicide
}

\author{
Jill Theresa Messing ${ }^{1}$ (D) Millan A. AbiNader ${ }^{1} \cdot$ Jesenia M. Pizarro ${ }^{2} \cdot J^{\prime} a c q u e l y n$ C. Campbell ${ }^{3} \cdot$ Megan Lindsay Brown $^{1}$. \\ Karissa R. Pelletier ${ }^{2}$
}

Accepted: 1 February 2021 / Published online: 25 February 2021

(C) The Author(s), under exclusive licence to Springer Science+Business Media, LLC part of Springer Nature 2021

\begin{abstract}
Despite the importance of intimate partner violence (IPV) and homicide research to women's health and safety, much remains unknown about risk factors for intimate partner homicide (IPH). This article presents the Arizona Intimate Partner Homicide Study, pilot research that is being conducted in one U.S. state to update and expand on risk factors for IPH. In the context of presenting this study, we summarize the literature on data collection techniques, various marginalized and under researched populations, and the importance of gathering data about the victim-offender relationship and situational IPH risk factors. Additional research is needed to update risk factors for IPH to account for changes in technology and to examine differential risk across diverse populations. Local, community based data collection strategies are likely to provide more comprehensive and nuanced insight into IPH; though, to understand risk factors among marginalized populations, it may be necessary to increase sample size through a national strategy. Although not a panacea, we present this ongoing research as a model for other states to emulate and improve upon, in the hopes of developing more comprehensive data examining risk for IPH among victims of IPV.
\end{abstract}

Keywords Intimate partner violence $\cdot$ Intimate partner homicide $\cdot$ Risk assessment

In the United States, intimate partner homicide (IPH) accounts for one-fifth of homicides overall (Jack et al. 2018). IPH is a gendered crime; approximately $40-50 \%$ of murdered women are killed by a current or former intimate partner compared to only 5-8\% of male homicide victims (Fridel and Fox 2019; Jack et al. 2018). Although the percent of homicides of men that were committed by an intimate partner decreased by $53 \%$ between 1980 and 2008, the percent of homicides of women committed by an intimate partner increased by $5 \%$ during this same period (Cooper and Smith 2011). Women with marginalized identities are at particular risk of femicide (the killing of

Jill Theresa Messing

Jill.Messing@asu.edu

1 School of Social Work, Arizona State University, 411 N Central Ave., Suite 800, Phoenix, AZ 85004, USA

2 School of Criminology and Criminal Justice, Arizona State University, Phoenix, AZ, USA

3 School of Nursing, Johns Hopkins University, Baltimore, MD, USA women), and by extension IPH. Femicide is the second leading cause of death for African American/Black girls and women ages 10-24 as well as the fourth leading cause of death for African American women between the ages of 25-34 (Heron 2019). Indigenous women are also killed at high rates; femicide is third leading cause of death for American Indian/ Alaskan native women 20-24 years old, and the fourth leading cause of death for American Indian/Alaskan native girls between the ages of 15-19 (Heron 2019).

Approximately two-thirds to three-quarters of women murdered by a current or former intimate partner are abused by that partner before being killed; and when women kill men, there has been prior intimate partner violence (IPV) against the female partner in approximately $75 \%$ of the cases (Campbell et al. 2003; Harden et al. 2019). The trajectory of serious IPV to IPH may be an increase in severity and frequency over time, culminating in homicide (Johnson 2006). Although there has been a proliferation of risk assessment instruments designed to predict IPV re-assault or re-arrest, only two (the Danger Assessment and the Severe Intimate Violence Partner Risk Prediction Scale) were 
designed to predict IPH (Campbell et al. 2009; Echeburúa et al. 2009; for a review of risk assessments see: Graham et al. 2019). IPH is difficult to predict, at least in part due to the relative rarity of IPH compared to other forms of violence. It would be enormously expensive, time consuming, and unethical to follow abusive couples (6.6 million women and 5.8 million men report victimization annually; Smith et al. 2018) over time to see which few end up as IPH cases (approximately 1500 women and 750 men were killed by an intimate partner in 2017; Fridel and Fox 2019).

As seen in Table 1, in studies that compare IPH and IPV risk, IPH data have been collected from case files in six studies, three collected information from offender interviews (Cunha and Goncalves 2016; Dobash et al. 2007; Echeburúa et al. 2009; Goussinsky and Yassour-Borochowitz 2012), and one collected data from proxy informants of the IPH victim (Campbell et al. 2003). In these same studies, data for the IPV samples were collected from perpetrators in five studies, from case files in two studies, and from IPV survivors in three studies. When compared to administrative data, data collected from individuals familiar with the relationship history of the IPH victim and perpetrator may lead to a more complete picture of the risk factors present in their relationship. Given the denial, minimization, and blame that are hallmarks of IPV, interviews with perpetrators alone may not present fully accurate pictures of relationship history and dynamics. Further, while the majority of manuscripts examined IPH as a unique outcome, three combined IPH and near-fatal IPV (e.g., strangulation) into a single outcome (Cunha and Goncalves 2016; Echeburúa et al. 2009; Goussinsky and Yassour-Borochowitz 2012; McFarlane et al. 2002a, 2002b).
Several qualitative studies have examined IPH cases to describe patterns of violence prior to the IPH and perpetrator motivation (for a review, see: Harden et al. 2019). While valuable, the lack of a comparison group in these studies makes it difficult to understand if these tactics are unique to IPH or are part of a larger continuum of IPV behavior. Only Goussinsky and Yassour-Borochowitz (2012), studying IPH in Israel, have qualitatively compared IPV and IPH perpetrator behavior. In order to identify and appropriately intervene in cases that may escalate to homicide, it is important for research to examine the progression from IPV to IPH.

Despite the substantial contributions of IPH research, limitations abound and additional research in the area is needed. Research has often lacked diverse samples, relied on case file data, and did not use advanced analytic techniques (for a synthesis of studies see: Harden et al. 2019; Spencer and Stith 2018). Researcher and practitioner knowledge of IPH and risk factors for IPH have progressed and national surveillance data have improved since much of the foundational research on IPH was done. The Campbell et al. (2003) 11-city femicide study, the only study to ask questions of IPH proxy informants, occurred over 20 years ago. In order to overcome some of the limitations of previous research, we have embarked upon a new series of IPH studies, beginning with the Arizona Intimate Partner Homicide (AzIPH) Study, a pilot replication of Campbell et al.' (2003) 11-site case-control intimate partner femicide study. In this commentary, we focus on the methodological contributions and limitations in this examination of IPH.

Table 1 IPH Risk Factor Research Studies

\begin{tabular}{|c|c|c|c|}
\hline Original Study & Place & Data Sources & Additional Publications \\
\hline (Alford 1995) & Detroit, USA & IPH case files; interviews with IPV victims & \\
\hline (Campbell et al. 2003) & 11 cities in USA & $\begin{array}{l}\text { IPH proxy informant interviews, } \\
\text { interviews with IPV victims }\end{array}$ & $\begin{array}{l}\text { (Block et al. 2000; } \\
\text { Campbell et al. 2003, 2009; } \\
\text { Glass et al. 2008a; } \\
\text { Glass et al. 2008b; } \\
\text { Koziol-Mclain et al. 2006; } \\
\text { McFarlane et al. 2002a, 2002b; } \\
\text { Sharps et al. 2001; } \\
\text { Taylor and Nabors 2009) }\end{array}$ \\
\hline (Cunha and Gonçalves 2019) & Portugal & IPH \& IPV perpetrator interviews & (Cunha and Goncalves 2016) \\
\hline (Dobash et al. 2007) & England & IPH case files; interviews with IPV perpetrators & \\
\hline (Dutton and Kerry 1999) & Canada & IPH case files; interviews with IPV perpetrators & \\
\hline (Echeburúa et al. 2009) & Basque, Spain & IPH \& IPV perpetrator interviews & \\
\hline (Eke et al. 2011) & Ontario, Canada & IPH \& IPV (near fatal) case files & \\
\hline (Goussinsky and Yassour-Borochowitz 2012) & Israel & IPH \& IPV perpetrator interviews & \\
\hline (Sanz-Barbero et al. 2016) & Spain & IPH case files, national survey on IPV & \\
\hline (Wiltsey 2008) & New Jersey, USA & IPH \& IPV case files & \\
\hline
\end{tabular}




\section{The Arizona Intimate Partner Homicide Study}

The AzIPH Study is pilot research, conducted in one U.S. state, intended to update data collection methods and capture information on heretofore underdeveloped risk factors. ${ }^{1}$ We present this ongoing research as a model for other states to emulate and improve upon, in the hopes of developing more comprehensive data examining risk for IPH among victims of IPV.

\section{Frequency of IPH}

The first objective of the AzIPH study is to obtain an accurate count of IPH in the study site through the triangulation of data from multiple sources. Although our initial data collection period was 2016-2019, we have permission from our partners to add data collection through 2020 in order to better understand changes in IPH rates due to COVID-19. We began by collecting data on all homicides from medical examiner's offices; medical examiners have larger jurisdictions than police departments, so we could gather comprehensive data on homicide with fewer data use and transfer agreements. Although the medical examiner data is comprehensive in terms of providing information on violent deaths $(2016-2019=1652)$, information about the context of the homicide is often sparse. As such, we moved on to gather additional contextual information from police departments. We are gathering these data for cases that we identified as an IPH $(n=151)$, as intimate partner related $(n=$ $95)$, or where the victim offender relationship is unknown $(n=$ $459)$ or unclear $(n=103)$. Comparisons of the data collected from these sources, including the amount and type of information available from each, will provide comparison information across place, population, and homicide type to identify the strengths and weaknesses of each data source.

The bulk of research on IPH in the U.S. has used datasets created through methods of case file data collection similar to those that we are using in Arizona. National homicide datasets compiled by the Center for Disease Control and Prevention (CDC) and the Federal Bureau of Investigation (FBI) have been critiqued for not accurately and consistently capturing intimate partner relationship data (Campbell et al. 2007; Pizarro and Zeoli 2013). Indeed, nuanced analyses of National Violent Death Reporting System (NVDRS) data indicate that IPV was a contrbuting factor in more violent deaths (10.3\%), including child homicides, than has previously been reported (Adhia et al. 2019; Kafka et al. 2020). Moreover, both the FBI Uniform Crime Reporting Supplementary Homicide Reports (UCR-SHR) and the CDC National

\footnotetext{
${ }^{1}$ Funding for this research was obtained from the Watts College of Public Service and Community Solutions at Arizona State University as part of a competitive process that sought proposals for community collaborative research.
}

NVDRS face issues of missing data (Fox and Swatt 2009; Swatt and Sabina 2013) and lack historical relational and behavioral factors (e.g., prior physical abuse, controlling behaviors, cohabitation history) that may provide a more complete picture of risk factors present prior to the homicide (Centers for Disease Control and Prevention 2016; Fox and Fridel 2016). In the NVDRS, only eight states and the District of Columbia currently collect data on the IPV module which records some relational (e.g., living together) and behavioral (e.g., suicidal ideation) factors included in case files (Centers for Disease Control and Prevention 2016; Rebecca Wilson, CDC, personal communication, August 20, 2019). In order to develop accurate assessments and interventions to prevent IPH, research must rely on data obtained through primary data collection efforts (i.e., researchers reviewing incident investigation reports, interviewing survivors and next of kin), which can offer a more complete picture of risk factors.

\section{Risk Factors for IPH}

The second objective of the study is to develop a better understanding of the specific risk factors for IPH, thus allowing criminal justice and social service agencies to develop and refine risk-informed approaches to reduce and prevent IPH. Arizona statute (A.R.S. § 13-3967(B)) requires that those making release decisions in domestic violence cases consider the results of a risk or lethality assessment and the rules of criminal procedure recommend a standard risk assessment across the state (Websdale et al. 2018). The risk assessment used in Arizona is derived from Campbell et al. (2003) femicide study and the ability of the risk assessment to predict near lethal violence was examined using data from the Oklahoma Lethality Assessment Study (Messing et al. 2015; Websdale 2020). The AzIPH study provides an opportunity to examine the ability of the risk assessment to predict homicide in the state and, as needed, to refine the risk assessment.

Relative to risk factors for repeat IPV, less is known about the risk factors for IPH or how IPV escalates to IPH. The 11city case control study is the only study to examine risk factors for IPH by gathering relationship histories of IPH victims given by proxy informants (i.e., people who were familiar with the intimate relationship of the IPH victim) and comparing these to the histories of a random sample of women who experienced non-fatal physical violence (Campbell et al. 2003). In the AzIPH study, we replicate these methods, identifying next of kin of the victims in IPH cases are from medical examiner records in order to reach proxy informants. In these medical examiner data, $72 \%$ of case files contained contact information for next of kin. The differential requirements of our collaborating agencies will allow us to test methodologies and response rates given various methods of contact (i.e., by researchers versus by medical examiners) and recruitment 
(i.e., called by researchers versus asked to contact researchers) of proxy informants.

In order to understand differences between IPH and IPV cases, we must also collect data on individuals who have experienced non-lethal physical IPV. In the 11-city femicide study, these participants were identified and surveyed through random digit dialing. With the rapid changes that have taken place over the past 20 years with widespread use of cellular phones (including texting), internet, and social media, as well as the decline in landline use, it is important to develop novel ways of gathering information from control participants (Blumberg and Luke 2019). Given these considerations, as well as the need to ensure a diverse control sample (e.g., gender identity, immigration status), new methodologies are being developed and tested.

The Campbell et al. (2003) study found that 19 risk factors (e.g., strangulation, forced sex, threats with a weapon) predicted IPH among women who were being abused by an intimate partner and provided the basis for the Danger Assessment (Campbell et al. 2003). Since these data were collected, researchers and practitioners have gathered additional information on potential risk factors. It is crucial that additional data are collected about firearm use, ownership, and access; protective orders (including emergency, long-term, criminal, and civil orders); technology-based abuse; and strangulation. These data cannot be reliably obtained in case files.

Firearm Ownership Firearm injuries are the most frequent cause of death in IPH cases (Campbell et al. 2007; Petrosky et al. 2017) and firearm IPH has increased 26\% since 2010 (Fridel and Fox 2019). Nearly all (91.6\%) intimate partnerrelated homicide-suicides are committed by firearm, which is disproportionate to the frequency of firearm-perpetrated homicide and suicide rates alone (Schwab-Reese and Peek-Asa 2019). In the $A Z$ medical examiner data where the cause of death is known (99.6\% of cases), $66.67 \%$ of IPH was committed with a firearm (compared to $71.02 \%$ of all homicides). Firearm ownership and threats with a firearm have consistently been shown to be a top risk factor of IPH and IPV re-assault (Matias et al. 2019). However, data on firearm ownership or possession (including type and number of firearms, how firearms were obtained, if firearms were removed, and victim firearm ownership) is not consistently recorded in case files. Nor is information about prior threats unless those threats were reported to the police. Despite being a critical factor in IPH, our understanding of the complexities of firearm ownership, access, and use as risk factors for IPH is limited.

Protection Orders Estimates of protection order use prior to IPH vary from a low of $2.6 \%$ to a high of $23 \%$ of IPH victims having an order of protection prior to or at the time of the IPH (Koppa and Messing 2019; McFarlane et al. 2001; Vittes and Sorenson 2008). A meta-analysis of the effectiveness of protection orders to reduce re-assault found that between $28.2 \%$ (police data) and $34.3 \%$ (survivor data) of orders were violated (e.g., arrest, physical violence; Cordier et al. 2019). In this meta-analysis, the majority of studies included samples where all women received protective orders; among those where there was variation, between $12 \%$ and $81 \%$ received orders (Cordier et al. 2019). Several risk factors associated with IPH are also associated with protection order violations including a history of IPV, arrests for IPV crimes, stalking behaviors, and economic strain (Campbell et al. 2003; Cordier et al. 2019). Further, it may be the case that certain types of violations are more predictive of IPH. Better understanding of protection order use and violation in relation to IPH is needed, particularly due to the ability of protection orders to limit firearm access.

Technology-Based Abuse Technology-based abuse is not considered in any IPV or IPH risk assessment instrument given the relative recency of research examining the intersection of technology and IPV. Indeed, although online abuse may be an indicator of increased IPH risk, data remains preliminary with research focusing on using qualitative or exploratory methods, mainly intended to define technology-based abuse (Brown et al. 2018; Douglas et al. 2019). Separation has been noted as a risk factor for IPH and technology-based abuse has been shown to escalate when victims separate from an abusive partner (Markwick et al. 2019). Further, across studies on IPV, technology is used as a tool of power and control (Dragiewicz et al. 2018), yet technology-based abuse reported by victims may be minimized or ignored when reported to law enforcement (Messing et al. 2020). As such, there is a dearth of information about the impacts of technology abuse, particularly as a risk factor for IPH.

Non-fatal Strangulation Data from the 11-city femicide study indicate that a history of non-fatal strangulation is associated with 7.48 times higher odds of later IPH of female victims compared to IPV victims who had no such history (Glass et al. 2008a). Several studies have suggested that female victims who experience strangulation once are likely to be strangled multiple times (Mcquown et al. 2016; Vella et al. 2017) and that multiple strangulation is associated with more severe violence and injury, acute PTSD symptoms, and additional risk factors for IPH compared to single attack victims (Messing et al. 2018). While there is a clear association between non-fatal strangulation and intimate partner femicide, strangulation may not leave any visible bruising and is often not reported to authorities. As such, the risk of IPH from multiple strangulation is not yet understood.

\section{Marginalized Groups}

The third objective of this study is to gain a better understanding of the frequency and descriptions of IPH among 
populations with marginalized identities, such as Indigenous peoples, those in same-sex relationships, transgender and gender non-conforming victims, male victims, foreign-born victims, military-involved victims, and rural populations. With the exception of one paper that utilized data from the Chicago site of the 11-city femicide study (Block et al. 2000) and included one same-sex IPH, research has only examined female victims of IPH perpetrated by male partners. Additionally, only one study stratified analyses by race (Glass et al. 2008a). Stratification is important because it controls for potential differences that various racial groups experience in the US and assists in the identification of unique risk profiles (Angrist and Pischke 2015). At the same time, it is important to ensure that marginalized groups are included in large enough numbers that stratification does not result in groups too small to meaningfully analyze (UIHI 2020). Risk factors for IPH likely differ among groups with marginalized identities in ways that cannot be captured in research design without such groups being purposefully sampled. Indeed, limited research has examined IPH risk factors unique to certain groups (e.g., citizenship status for foreign-born individuals). It is imperative to include risk factors unique to marginalized groups and to account for between-group differences due to structural factors while modeling IPH risk.

The AzIPH Study is not excluding cases or controls based on gender, sexual orientation, race/ethnicity, or immigration status. We have included medical examiners and law enforcement agencies in rural areas despite the additional difficulties this has posed due to limited budgets, difficult-to-reach locations, and small samples in some rural jurisdictions. We recently received funding to expand the AzIPH study to include multiple states and increase sample size, but the small number of people that may be included across some marginalized populations indicate the need for a national strategy to understand risk for IPH in these groups. At the same time, one of the tenets of the AzIPH study is that local and community based data collection strategies are more effective, creating a juxtaposition between this tenet and the need to increase the sample size for marginalized groups. As a complimentary strategy, we have developed multiple supplements to the interview guide that include risk factors that may be specific to different populations. These include supplements for LGB, transgender, and immigrant victims, as well as a supplement for couples who were recently separated and going through a divorce. Using a confirmatory mixed methods approach, we are collecting qualitative data from the IPH proxy interviews in order to qualitatively analyze risk factors among these groups if we do not reach adequate numbers for quantitative analysis. Given the multiple vulnerabilities faced by some demographic and geographic groups, research must attend to risk for IPH among marginalized populations; some specific examples are outlined below.
Indigenous People Both indigenous men and women are victims of homicide at a disproportionate rate compared to other racial/ethnic groups (Heron 2019). Data from 71 U.S. cities found 280 homicides of indigenous women in 2016 (Lucchesi and Echo-Hawk 2018). Examining IPH specifically, CDC data indicate that $55.4 \%$ of all indigenous femicide victims are murdered by an intimate partner (Petrosky et al. 2017). Misclassification of the racial identities of Indigenous people within systems that commonly gather data leads to undercounts of murdered and missing indigenous women and girls (MMIWG; Echo-Hawk et al. 2019). Within the AzIPH study, we will triangulate data on racial/ethnic identities by collecting this information from the medical examiner, police reports, and interview participants in an effort to correct racial misclassifications (UIHI 2020).

Given both the high rates of IPV and the epidemic of MMIWG (Lucchesi and Echo-Hawk 2018), more research examining IPH risk factors specific to this oppressed population is needed. Further, studies have identified that, at least in part due to racist policies and practices, indigenous populations experience high rates of known IPV risk factors (e.g., unemployment) and systemic barriers to accessing resources like legal and victim services (Wahab and Olson 2004). Statespecific examinations are necessary but not sufficient to understand risk factors for IPH among Indigenous people as genocide has resulted in low numbers of Indigenous women in the U.S. population. Arizona, for example, has the 7th highest proportion of American Indian / Alaska Native (AI/ AN) people, yet only $4.46 \%$ of the population is identified as AI/AN (American Community Survey 2018). As such coordinating across the U.S. states is imperative; understanding the stories of Indigenous victims of IPH will take a concerted effort that involves data collection practices that are community based, culturally informed, and conducted in tandem with MMIWG policies and activities.

Victims in Same-Sex Relationships Studies of IPV prevalence among lesbian, gay, and bisexual (LGB) individuals have consistently found that LGB individuals experience IPV at similar or higher rates than heterosexual individuals (Edwards and Neal 2015; Gehring and Vaske 2017; Walters et al. 2013). With notable exceptions (Gersetenberger 2017; Glass et al. 2008c; Hilton et al. 2014; Jung and Buro 2016), the majority of IPH and IPV risk assessment studies have examined risk for both future violence and fatality among different-sex couples. Prior research has identified several risk factors specific to LGB individuals such as internalized homophobia, minority stress, and fear of discrimination due to stigma (Edwards and Neal 2015; Glass et al. 2008c; Kimmes et al. 2019). LGB people are estimated to be $4.14 \%$ of the U.S. adult population, with state ranges from $2.40 \%$ (ND) to $8.03 \%$ (DC) (Williams Institute 2019). Although there are approximately 10 million LGB people throughout the U.S., any state- 
based investigation will not provide a large enough sample of IPH to understand risk factors. Of the medical examiner data collected from the AzIPH study, five incidents were identified as same-sex IPH out of the 151 IPH incidents identified.

Transgender and Gender Non-conforming Victims There are approximately 1.4 million transgender individuals in the U.S., 400,000 of whom also identify as LGB (Williams Institute 2019). Research on experiences of IPV and IPH among transgender and gender non-conforming victims is particularly limited, though it appears that transgender and gender-diverse individuals, particularly Black, Latina, and Indigenous trans women, are murdered at high rates (Transrespect versus Transphobia Worldwide 2019). Indeed, the number of trans women of color killed in the U.S. rose steadily between 2012 and 2017 (Waters et al. 2018). Further, a Colorado study of IPV rates found that transgender and gender non-conforming individuals report lifetime IPV at significantly higher rates than cisgender individuals $(31.1 \%$ v. $20.4 \%$; LangenderferMagruder et al. 2016). While the NVDRS added a transgender variable in 2013 (Centers for Disease Control and Prevention 2016), the UCR-SHR only captures binary sex (Fox and Fridel 2016), limiting national estimates of IPH of transgender and gender non-confirming victims. National research is needed that includes gender identities beyond the binary and captures the abusive tactics that may be unique to transgender and gender non-conforming individuals (Yerke and DeFeo 2016). There was one case of a transgender individual who was killed by an intimate partner identified in the four years of the AzIPH data.

Male Victims No IPH risk assessments have been developed for male victims, although re-assault risk assessments have been tested for male victims in different-sex relationships (Hilton et al. 2014) and same-sex relationships (Gerstenberger et al. 2019; Jung and Buro 2016). IPH makes up less than $10 \%$ of all homicides of male victims (Fridel and Fox 2019; Jack et al. 2018) and men report less IPV-related impact than women (D'Inverno et al. 2019). Although less common, studies of male IPV victims indicate that they experience many of the same abuse tactics and adverse outcomes as female victims (Reid et al. 2008). Out of 151 identified IPH incidents in Arizona, 39 victims were male. However, research has also indicated that men killed by an intimate partner are likely to have abused that partner prior to the homicide (Harden et al. 2019), making it important to tease out the precipitators and risk for IPH among men. We are carefully reviewing case file data to identify if there was IPV against the homicide perpetrator leading up to the homicide. In these cases, we will consider interviewing the homicide perpetrator about prior IPV, potentially in addition to the IPH victim's next of kin. Including male victims in studies of IPH risk is critical to providing information about whether risk and protective factors (e.g., coercive control, firearm access) are consistent or inconsistent across gender, and for understanding the interplay between victimization and perpetration in these cases.

Foreign-Born Victims While the Danger Assessment has been adapted with risk factors specific to foreign-born populations to predict re-assault and severe re-assault among female victims, there is not yet any IPH risk assessment for foreign-born victims (Messing et al. 2013). Studies have shown that foreign-born victims are much more likely to be murdered by an intimate partner than by someone else (Sabri et al. 2018). Other studies have shown that foreign-born victims have higher injury rates (Lee and Hadeed 2009) and these injury rates are highest among those with low acculturation, little to no social support, and who do not have family in the U.S. (Raj and Silverman 2003). Similar to other marginalized groups, foreign-born victims face several structural barriers to accessing help, particularly with regard to their often-tenuous legal status, making them a population at heightened risk of IPV escalating to IPH. Studies of risk factors specific to IPH are critical to creating assessments that can be utilized in culturally-specific services. In Arizona, we will offer the interview in English and Spanish; it is important to include additional languages and we will prioritize this as resources allow.

Military-Involved Victims Currently, only one IPV risk assessment, predicting re-assault, is specific to the military; there is currently no military-specific risk assessment for IPH and there is a dearth of literature about IPH among military personnel or partners of military personnel (Stith et al. 2016). IPV prevalence estimates among military-involved populations vary widely (Rentz et al. 2006), depending on the group assessed (e.g., active duty women, wives of active duty men) and sampling frame (Black and Merrick 2013; Dichter et al. 2015). Several studies have also indicated a positive association between deployment and IPV, with recent deployment significantly associated with IPV perpetration among male active duty members (Rabenhorst et al. 2012) and victimization among recently deployed female active duty members (Black and Merrick 2013). IPH research that considers risk factors unique to military populations (e.g., combatrelated stress) is needed to inform risk assessment and intervention development among this unique population.

Rural Victims Existing IPH risk assessment instruments did not systematically sample rural populations and, therefore, were unable to compare potential urban-rural differences during the creation and validation processes (Campbell et al. 2003; Echeburúa et al. 2009). However, rural victims of IPV may be at heightened risk of IPH, as research indicates that rural IPV is more frequent, severe, and lethal than urban IPV 
(DuBois et al. 2019; Edwards 2015). Rural IPV victims face numerous barriers to accessing legal, social, and medical services including limited transportation, physical isolation, privacy and confidentiality issues, lack of services, and underresourced service agencies (Johnson et al. 2014; Peek-Asa et al. 2011). When considering rural IPH, firearm access and use may be a particularly potent risk factor: rural intimate partner femicide victims are more likely to be killed with a firearm than those in urban areas (Reckdenwald et al. 2019). Moreover, firearms are highly accessible in rural areas; $46 \%$ of rural U.S. adults own a firearm, compared to $28 \%$ of suburban adults and 19\% of urban adults (Parker et al. 2017). In Arizona, the majority of homicides that occurred in rural areas were covered by two medical examiners because the smaller medical examiner's offices did not have the capacity or equipment for homicide investigations. With increased geographic diversity in our sample, we will be able to examine if there are place-specific risk factors that lead to IPH.

\section{Conclusion}

Despite the importance of IPV and IPH research to women's health and safety, much remains unknown about risk factors for IPH. Data collection for the last case-control research study that interviewed proxies of IPH in the U.S. to examine the risk factors for IPH was conducted over 20 years ago. Moreover, gaps remain in the literature, few studies have compared risk of IPH and IPV using quantitative or qualitative methods, and there is limited data on IPH risk specific to marginalized populations despite the vulnerabilities faced by these groups.

The AzIPH Study begins to address these gaps in the literature by employing a novel approach to collecting and triangulating data from various sources in a single state. Our approach of collecting data throughout an entire state, instead of just a municipality or county within a state, allows us to begin to understand IPH risk among marginalized groups in a way that prior research has not. Furthermore, our ability to triangulate data sources, incorporating data from multiple official records and interviews with next of kin, is likely to provide a more nuanced understanding of IPH, homicides related to IPV, and homicide among marginalized populations. Arizona has a diverse population, including various urban, suburban, rural, and Indigenous/Native American lands with 21 federally recognized tribes. While it is not likely that data collection in one state will provide enough data to understand risk factors for each marginalized group, data collection in AZ will allow us to better understand the scope of the problem, describe IPH risk factors for marginalized groups in relation to prior samples, and provide information on the additional data collection needed. Local and community based data collection efforts provide an opportunity to identify nuances that may be lost across larger data collection efforts. It is expected that these methods will allow for a more holistic understanding of the progression of IPV to IPH and the identification of potential risk factors among marginalized populations.

There is a need to expand the knowledge base on relational and situational risk factors for IPH and survey development considered the diverse and complex life circumstances of IPH victims and offenders to better capture risk factors across groups. We have developed additional risk questions that address the under-researched risk factors including: firearm use, ownership, and access; protection orders; technology abuse; strangulation; and risk factors unique to particular groups. Items were developed from existing scales that have not yet been examined in relation to IPH (e.g., Peitzmeier et al. 2019), using previous literature on risk factors (e.g., Sabri et al. 2018), and practice wisdom. Additionally, several openended questions were included to solicit potential risk factors that the research team may not have considered in survey creation (Dekeseredy 2019). Before implementing our interview guide, we will conduct cognitive testing with proxy informants to better refine and streamline the interview. Our nuanced data collection and methodological approach allows for a comprehensive understanding of IPH that begins to answer some of the current pressing questions in the area.

The anti-violence community - both practitioners and researchers - are eager for an updated examination of this topic. Given changes in criminal justice and social service agencies, as well as changes that have occurred within society (e.g., widespread use of the internet) over the past 20 years, it is important to pilot research methods before examining risk factors for IPH at a national level. Consequently, it is important for researchers to continue examining this pressing issue with novel research approaches that address the current gaps in the knowledge base and contribute to the literature. This article outlined the various gaps that remain in the literature and discussed the AzIPH study, which was methodologically designed to address some of these gaps in knowledge. Researchers should continue on this path and model the techniques and approaches outlined here as part of the AzIPH study in order to assist in the development of more accurate risk assessment and interventions to protect vulnerable IPV victims. Researchers working together across multiple states using consistent methods may have an opportunity to expand the AzIPH study to more accurately reflect the diversity of the U.S.

\section{References}

Adhia, A., Austin, S. B., Fitzmaurice, G. M., \& Hemenway, D. (2019). The role of intimate partner violence in homicides of children aged 2-14 years. American Jurnal of Preventative Medicine, 56(1), 3846. 
Alford, P. A. (1995). A comparative study of women in abusive situations who have been battered or victims of homicide and the perceptions of professional groups working with abused women - ProQuest. Wayne State University.

American Community Survey. (2018). ACS Demographic and Housing Estimates Table DP05. https://data.census.gov/

Angrist, J. D., \& Pischke, J. S. (2015). Mastering 'metrics: The path from cause to effect. Princeton University Press.

Black, M. C., \& Merrick, M. T. (2013). Prevalence of Intimate Partner Violence, Stalking, and Sexual Violence Among Active Duty Women and Wives of Active Duty Men-Comparisons with Women in the U.S. General Population, 2010 Technical Report. https://apps.dtic.mil/ dtic/tr/fulltext/u2/a582205.pdf

Block, C. R., Devitt, C. O., Fugate, M., Martin, C., Pasold, T., Fonda, D., Engel, B., Naureckas, S. M., Riordan, K. A., McFarlane, J., \& Walker, G. R. (2000). "The Chicago Women's health risk study, risk of serious injury or death in intimate violence: A collaborative research project.

Blumberg, S. J., \& Luke, J. V. (2019). Wireless Substitution: Early Release of Estimates From the National Health Interview Survey, July-December 2018. https://www.cdc.gov/nchs/data/nhis/ earlyrelease/wireless201906.pdf

Brown, M. L., Reed, L. A., \& Messing, J. T. (2018). Technology-based abuse: Intimate partner violence and the use of information communication technologies. In Mediating Misogyny (pp. 209-227). Palgrave Macmillan.

Campbell, J. C., Glass, N., Sharps, P. W., Laughon, K., \& Bloom, T. (2007). Intimate partner homicide: Review and implications of research and policy. Trauma, Violence, and Abuse, 8(3), 246-269.

Campbell, J. C., Webster, D., Koziol-McLain, J., Block, C., Campbell, D., Curry, M. A., Gary, F., Glass, N., McFarlane, J., Sachs, C., Sharps, P., Ulrich, Y., Wilt, S. A., Manganello, J., Xu, X., Schollenberger, J., Frye, V., \& Laughon, K. (2003). Risk factors for Femicide in abusive relationships: Results from a multisite case control study. American Journal of Public Health, 93(7), 10891097.

Campbell, J. C., Webster, D. W., \& Glass, N. (2009). The danger assessment: Validation of a lethality risk assessment instrument for intimate partner Femicide. Journal of Interpersonal Violence, 24(4), 653-674.

Centers for Disease Control and Prevention. (2016). National Violent Death Reporting System (NVDRS) Coding Manual Revised. https://www.cdc.gov/violenceprevention/pdf/nvdrs_web_ codingmanual.pdf

Cooper, A., \& Smith, E. L. (2011). Homicide trends in the United States, 1980-2008.

Cordier, R., Chung, D., Wilkes-Gillan, S., \& Speyer, R. (2019). The effectiveness of protection orders in reducing recidivism in domestic violence: A systematic review and meta-analysis. Trauma, Violence, and Abuse., 152483801988236.

Cunha, O. S., \& Goncalves, R. A. (2016). Severe and less severe intimate partner violence: From characterization to prediction. Violence and Victims, 31(2), 235-250.

Cunha, O. S., \& Gonçalves, R. A. (2019). Predictors of intimate partner homicide in a sample of Portuguese male domestic offenders. Journal of Interpersonal Violence, 34(12), 2573-2598.

D'Inverno, A. S., Smith, S. G., Zhang, X., \& Chen, J. (2019). The Impact of Intimate Partner Violence: A 2015 NISVS Research-in-Brief. https://www.cdc.gov/violenceprevention/pdf/nisvs/nisvsimpactbrief-508.pdf

Dekeseredy, W. S. (2019). Innovative methods of gathering survey data on violence against women. In Sociology of Crime Law and Deviance (Vol. 24, pp. 69-84). Emerald Group publishing ltd.

Dichter, M. E., Wagner, C., \& True, G. (2015). Timing of intimate partner violence in relationship to military service among women veterans. Military Medicine, 180(11), 1124-1127.
Dobash, R. E., Dobash, R. P., Cavanagh, K., \& Medina-Ariza, J. (2007). Lethal and nonlethal violence against an intimate female partner. Violence Against Women, 13(4), 329-353.

Douglas, H., Harris, B. A., \& Dragiewicz, M. (2019). Technologyfacilitated domestic and family violence: Women's experiences. The British Journal of Criminology, 59(3), 551-570.

Dragiewicz, M., Burgess, J., Matamoros-Fernández, A., Salter, M., Suzor, N. P., Woodlock, D., \& Harris, B. (2018). Technology facilitated coercive control: Domestic violence and the competing roles of digital media platforms. Feminist Media Studies, 18(4), 609-625.

DuBois, K. O., Rennison, C. M., \& DeKeseredy, W. S. (2019). Intimate partner violence in small towns, dispersed rural areas, and other locations: Estimates using a Reconception of settlement type. Rural Sociology, Online Fir.

Dutton, D. G., \& Kerry, G. (1999). Modus operandi and personality disorder in incarcerated spousal killers. International Journal of Law and Psychiatry, 22(3-4), 287-299.

Echeburúa, E., Fernández-Montalvo, J., de Corral, P., López-Gońi, J. J., \& López-Goñi, J. J. (2009). Assessing risk markers in intimate partner Femicide and severe violence. Journal of Interpersonal Violence, 24(6), 925-939.

Echo-Hawk, A., Dominguez, A. \& Echo-Hawk, L. (2019). MMIWG: We demand more. Retrieved from: https://www.uihi.org/download/ mmiwg-we-demand-more $/$ ? wpdmdl $=15826 \&$ refresh $=$ 5fe4c16be15ff1608827243. Accessed 1/7/2021.

Edwards, K. M. (2015). Intimate partner violence and the rural-urbansuburban divide: Myth or reality? A critical review of the literature. Trauma, Violence, and Abuse, 16(3), 359-373.

Edwards, K. M., \& Neal, A. M. (2015). Intimate partner violence among sexual minority populations: A critical review of the literature and agenda for future research.

Eke, A. W., Hilton, N. Z., Harris, G. T., Rice, M. E., \& Houghton, R. E. (2011). Intimate partner homicide: Risk assessment and prospects for prediction. Journal of Family Violence, 26(3), 211-216.

Fox, J. A., \& Fridel, E. E. (2016). Codebook for the multiply-imputed supplementary homicide reports file 1976-2016. School of Criminology and Criminal Justice, Northeastern University.

Fox, J. A., \& Swatt, M. L. (2009). Multiple imputation of the supplementary homicide reports, 1976-2005. Journal of Quantitative Criminology, 25(1), 51-77.

Fridel, E. E., \& Fox, J. A. (2019). Gender differences in patterns and trends in U.S. homicide, 1976-2017. Violence and Gender, 6(1), $27-36$.

Gehring, K. S., \& Vaske, J. C. (2017). Out in the open: The consequences of intimate partner violence for victims in same-sex and oppositesex relationships. Journal of Interpersonal Violence, 32(23), 36693692.

Gersetenberger, C. B. (2017). Gender, sexual orientation, and intimate partner violence: An analysis of risk and recidivism. Riverside: University of California.

Gerstenberger, C., Stansfield, R., \& Williams, K. R. (2019). Intimate partner violence in same-sex relationships: An analysis of risk and Rearrest. Criminal Justice and Behavior, 46(11), 1515-1527.

Glass, N., Laughon, K., Campbell, J., Block, C. R., Hanson, G., Sharps, P. W., \& Taliaferro, E. (2008a). Non-fatal strangulation is an important risk factor for homicide of women. The Journal of Emergency Medicine, 35(3), 329-335.

Glass, N., Laughon, K., Rutto, C., Bevacqua, J., \& Campbell, J. C. (2008b). Young adult intimate partner femicide: An exploratory study. Homicide Studies, 12(2), 177-187.

Glass, N., Perrin, N., Hanson, G., Bloom, T., Gardner, E., \& Campbell, J. C. $(2008 \mathrm{c})$. Risk for reassault in abusive female same-sex relationships. American Journal of Public Health, 98(6), 1021-1027.

Goussinsky, R., \& Yassour-Borochowitz, D. (2012). "I killed her, but I never laid a finger on her" - A phenomenological difference 
between wife-killing and wife-battering. Aggression and Violent Behavior, 17(6), 553-564.

Graham, L. M., Sahay, K. M., Rizo, C. F., Messing, J. T., \& Macy, R. J. (2019). The validity and reliability of available intimate partner homicide and Reassault risk assessment tools: A systematic review. Trauma, Violence, \& Abuse, Online First

Harden, J., Du, J., Spencer, C. M., \& Stith, S. M. (2019). Examining attempted and completed intimate partner homicide: A qualitative synthesis. Violence and Victims, 34(6), 869-888.

Heron, M. (2019). Deaths: Leading causes for 2017. National Vital Statistics Reports, 68(6), 1-77.

Hilton, N. Z., Popham, S., Lang, C., \& Harris, G. T. (2014). Preliminary validation of the ODARA for female intimate partner violence offenders. Partner Abuse, 5(2), 189-203.

Jack, S. P. D., Petrosky, E., Lyons, B. H., Blair, J. M., Ertl, A. M., Sheats, K. J., \& Betz, C. J. (2018). Surveillance for violent deaths National Violent Death Reporting System, 27 states, 2015. MMWR. Surveillance Summaries, 67(11), 1-32.

Johnson, M. (2006). Conflict and control: Gender, symmetry, and asymmetry in domestic violence. Violence Against Women, 12(11), $1003-1018$

Johnson, M., McGrath, S. A., \& Miller, M. H. (2014). Effective advocacy in rural domains. Journal of Interpersonal Violence, 29(12), 21922217.

Jung, S., \& Buro, K. (2016). Appraising risk for intimate partner violence in a police context. Criminal Justice and Behavior, 44(2), 240-260.

Kafka, J., Moracco, B., Young, B., Taheri, C., Graham, L.M., Macy, R., Proescholdbell, S. (2020). Fatalities related to intimate partner violence: Towards a comprehensive perspective. Injury Prevention. Published online first: 24 august 2020. doi: https://doi.org/10. 1136/injuryprev-2020-043704.

Kimmes, J. G., Mallory, A. B., Spencer, C., Beck, A. R., Cafferky, B., \& Stith, S. M. (2019). A meta-analysis of risk markers for intimate partner violence in same-sex relationships. Trauma, Violence, and Abuse, 20(3), 374-384.

Koppa, V., \& Messing, J. T. (2019). Can justice system interventions prevent intimate partner homicide? An analysis of rates of help seeking prior to fatality. Journal of Interpersonal Violence, Online First.

Koziol-Mclain, J., Webster, D., McFarlane, J., Block, C. R., Ulrich, Y., Glass, N., \& Campbell, J. C. (2006). Risk factors for Femicidesuicide in abusive relationships: Results from a multisite case control study. Violence and Victims, 21(1), 3-21.

Langenderfer-Magruder, L., Whitfield, D. L., Walls, N. E., Kattari, S. K., \& Ramos, D. (2016). Experiences of intimate partner violence and subsequent police reporting among lesbian, gay, bisexual, transgender, and queer adults in Colorado: Comparing rates of Cisgender and transgender victimization. Journal of Interpersonal Violence, 31(5), 855-871.

Lee, Y. S., \& Hadeed, L. (2009). Intimate partner violence among asian immigrant communities: Health/ mental health consequences, helpseeking behaviors, and service utilization. Trauma, Violence, and Abuse, 10(2), 143-170. https://doi.org/10.1177/ 1524838009334130 .

Lucchesi, A., \& Echo-Hawk, A. (2018). Missing and murdered indigenous women and girls: A snapshot of data from 71 urban cities in the U.S. https://www.uihi.org/wp-content/uploads/2018/11/Missingand-Murdered-Indigenous-Women-and-Girls-Report.pdf

Markwick, K., Bickerdike, A., Wilson-Evered, E., \& Zeleznikow, J. (2019). Technology and family violence in the context of postseparated parenting. Australian and New Zealand Journal of Family Therapy, 40(1), 143-162.

Matias, A., Gonçalves, M., Soeiro, C., \& Matos, M. (2019). Intimate partner homicide: A meta-analysis of risk factors. Aggression and Violent Behavior, 302, 101358.
McFarlane, J., Campbell, J. C., \& Watson, K. (2001). The use of the justice system prior to intimate partner Femicide. Criminal Justice Review, 26(2), 193-208.

McFarlane, J., Campbell, J. C., \& Watson, K. (2002a). Intimate partner stalking and femicide: Urgent implications for women's safety. Behavioral Sciences \& the Law, 20(1-2), 51-68.

McFarlane, J., Campbell, J. C., \& Watson, K. (2002b). Abuse during pregnancy and femicide: Urgent implications for women's health. Obstetrics \& Gynecology, 100(1), 27-36.

Mcquown, C., Frey, J., Steer, S., Fletcher, G. E., Kinkopf, B., Fakler, M., \& Prulhiere, V. (2016). Prevalence of strangulation in survivors of sexual assault and domestic violence. The American Journal of Emergency Medicine, 34(7), 1281-1285.

Messing, J., Bagwell-Gray, M., Brown, M. L., Kappas, A., \& Durfee, A. (2020). Intersections of stalking and technology-based abuse: Emerging definitions, conceptualization, and measurement. Journal of Family Violence, 1-12.

Messing, J. T., Amanor-Boadu, Y., Cavanaugh, C. E., Glass, N. E., \& Campbell, J. C. (2013). Culturally competent intimate partner violence risk assessment: Adapting the danger assessment for immigrant women. Social Work Research, 37(3), 263-275.

Messing, J. T., Patch, M., Wilson, J. S., Kelen, G. D., \& Campbell, J. (2018). Differentiating among attempted, completed, and multiple nonfatal strangulation in women experiencing intimate partner violence. Women's Health Issues, 28(1), 104-111.

Messing, J. T., Campbell, J., Webster, D. W., Brown, S., Patchell, B., \& Wilson, J. S. (2015). The Oklahoma lethality assessment study: A quasi-experimental evaluation of the lethality assessment program. Social Service Review, 89(3), 499-530.

Parker, K., Horowitz, J., Igielnik, R., Oliphant, B., \& Brown, A. (2017). America's complex relationship with guns: An in-depth look at the attitudes and experiences of U.S. adults (issue June). http://www. pewsocialtrends.org/2017/06/22/americas-complex-relationshipwith-guns/

Peek-Asa, C., Wallis, A., Harland, K., Beyer, K., Dickey, P., \& Saftlas, A. (2011). Rural disparity in domestic violence prevalence and access to resources. Journal of Women's Health, 20(11), 1743-1749.

Peitzmeier, S. M., Hughto, J. M. W. W., Potter, J., Deutsch, M. B., \& Reisner, S. L. (2019). Development of a novel tool to assess intimate partner violence against transgender individuals. Journal of Interpersonal Violence, 34(11), 2376-2397. https://doi.org/10. 1177/0886260519827660.

Petrosky, E., Betz, C. J., Fowler, K. A., Jack, S. P. D., Blair, J. M., \& Lyons, B. H. (2017). Racial and ethnic differences in homicides of adult women and the role of intimate partner violence - United States, 2003-2014. Morbidity and Mortality Weekly Report, 66(28), 741-746.

Pizarro, J. M., \& Zeoli, A. M. (2013). An assessment of the quality of homicide data in the supplementary homicide reports: A research note. Justice Quarterly, 30(4), 711-731.

Rabenhorst, M. M., Thomsen, C. J., Milner, J. S., Foster, R. E., Linkh, D. J., \& Copeland, C. W. (2012). Spouse abuse and combat-related deployments in active duty air force couples. Psychology of Violence, 2(3), 273-284.

Raj, A., \& Silverman, J. G. (2003). Immigrant south Asian women at greater risk for injury from intimate partner violence. American Journal of Public Health, 93(3), 435-437.

Reckdenwald, A., Szalewski, A., \& Yohros, A. (2019). Place, injury patterns, and female-victim intimate partner homicide. Violence Against Women, 25(6), 654-676.

Reid, R. J., Bonomi, A. E., Rivara, F. P., Anderson, M. L., Fishman, P. A., Carrell, D. S., \& Thompson, R. S. (2008). Intimate partner violence among men. Prevalence, chronicity, and health effects. American Journal of Preventive Medicine, 34(6), 478-485. 
Rentz, E. D., Martin, S. L., Gibbs, D. A., Clinton-Sherrod, M., Hardison, J., \& Marshall, S. W. (2006). Family violence in the military: A review of the literature. Trauma, Violence \& Abuse, 7(2), 93-108.

Sabri, B., Campbell, J. C., \& Messing, J. T. (2018). Intimate partner homicides in the United States, 2003-2013: A comparison of immigrants and nonimmigrant victims. Journal of Interpersonal Violence, Online First.

Sanz-Barbero, B., Heras-Mosterio, J., Otero-García, L., \& Vives-Cases, C. (2016). Perfil sociodemográfico del feminicidio en España y su relación con las denuncias por violencia de pareja. Gaceta Sanitaria, 30(4), 272-278.

Schwab-Reese, L. M., \& Peek-Asa, C. (2019). Factors contributing to homicide-suicide: Differences between firearm and non-firearm deaths. Journal of Behavioral Medicine, 42(4), 681-690.

Sharps, P. W., Campbell, J., Campbell, D., Gary, F., \& Webster, D. (2001). The role of alcohol use in intimate partner femicide. American Journal on Addictions, 10(2), 122-135.

Smith, S. G., Zhang, X., Basile, K. C., Merrick, M. T., Wang, J., Kresnow, M., \& Chen, J. (2018). The National Intimate Partner and Sexual Violence Survey: 2015 Data Brief - Updated Release. cdc.gov/violenceprevention/pdf/2015data-brief508.pdf.

Spencer, C. M., \& Stith, S. M. (2018). Risk factors for male perpetration and female victimization of intimate partner homicide: A meta-analysis. Trauma, Violence, and Abuse, 21(3), 527-540.

Stith, S. M., Milner, J. S., Fleming, M., Robichaux, R. J., \& Travis, W. J. (2016). Intimate partner physical injury risk assessment in a military sample. Psychology of Violence, 6(4), 529-541.

Swatt, M., \& Sabina, C. (2013). Summary Report: Latino Intimate Partner Homicide. https://www.ncjrs.gov/pdffiles1/nij/grants/ 248887.pdf

Taylor, R., \& Nabors, E. L. (2009). Pink or blue... black and blue? Examining pregnancy as a predictor of intimate partner violence and femicide. Violence Against Women, 15(11), 1273-1293.

Transrespect versus Transphobia Worldwide. (2019). TMM Update Trans Day of Remembrance 2019. https://transrespect.org/en/tmmupdate-trans-day-of-remembrance-2019/

Urban Indian Health Institute (2020). Best practices for American Indian and Alaska Native data collection. Retrieved 1/7/2021: https://www. uihi.org/download/best-practices-for-american-indian-and-alaskanative-data-collection $/$ ? wpdmdl $=16644 \&$ refresh $=$ 5 fe4c0b21797f1608827058
Vella, S. A., Miller, M. M., Lambert, J. E., \& Morgan, M. L. (2017). "I felt close to death": A phenomenological study of female strangulation survivors of intimate terrorism. Journal of Feminist Family Therapy, 29(4), 171-188.

Vittes, K. A., \& Sorenson, S. B. (2008). Restraining orders among victims of intimate partner homicide. Injury Prevention: Journal of the International Society for Child and Adolescent Injury Prevention, 14(3), 191-195.

Wahab, S., \& Olson, L. (2004). Intimate partner violence and sexual assault in native American communities. Trauma, Violence, \& Abuse, 5(4), 353-366.

Walters, M. L., Chen, J., \& Breiding, M. J. (2013). The National Intimate Partner and Sexual Violence Survey: 2010 Findings on Victimization by Sexual Orientation. cdc.gov/violenceprevention/ pdf/nisvs_sofindings.pdf.

Waters, E., Pham, L., Convery, C., \& Yacka-Bible, S. (2018). A crisis of hate: A report on lesbian, gay, bisexual, transgender and queer hate violence homicides in 2017. https://avp.org/wp-content/uploads/ 2018/01/a-crisis-of-hate-january-release.pdf

Websdale, N. (2020). Community-informed risk assesmsent in intimate partner violence and abuse cases: Origins, developmen, and deployment. In R. Geffner, J. W. White, L. K. Hamberger, A. Rosenbaum, V. Vaughan-Eden, \& V. I. Vieth (Eds.), Handbook of interpersonal violence and abuse across the lifespan. New York: Springer Nature.

Websdale, N., Monahan, J. \& Giangobbe, G. (2018). Protecting victims of intimate partner violence: Arizona's emerging risk assessment model. The Police Chief, 42-47.

Williams Institute. (2019). Adult LGBT Population in the United States. https://williamsinstitute.law.ucla.edu/wp-content/uploads/LGBTAdult-US-Pop-Mar-2019.pdf

Wiltsey, M. T. (2008). Risk factors for intimate partner homicide. Drexel University.

Yerke, A. F., \& DeFeo, J. (2016). Redefining intimate partner violence beyond the binary to include transgender people. Journal of Family Violence, 31(8), 975-979.

Publisher's Note Springer Nature remains neutral with regard to jurisdictional claims in published maps and institutional affiliations. 